\title{
New Insights into Kinetics of PETN Decomposition from the Product and Reactant Point of View: An Investigation with Mass Spectrometry and Differential Scanning Calorimetry
}

\author{
Sanjoy K Bhattacharia ${ }^{* a}$, Jay Nunley ${ }^{\mathrm{a}}$, Brandon L Weeks ${ }^{\mathrm{a}}$ \\ ${ }^{a}$ Department of Chemical Engineering, Texas Tech University Lubbock,TX-79409,USA. \\ *Corresponding Author \\ *Email: sanjoy.k.bhattacharia@gmail.com
}

\begin{abstract}
:
Pentaerythritol Tetranitrate (PETN) is a benchmark organic energetic material and is used in both military and industrial applications. Accurate kinetic parameters for the decomposition of energetic materials are required to predict the hazards, thermal cook-off and properties of PETN. Kinetic parameters of PETN decomposition have been previously reported in wide range of values. We are attempting to find new insights on the the kinetics of PETN decompsition by studying kinetics of gas evolution and heat released from the reaction. Gas evolution kinetics is studied by a mass spectrometer coupled with a thermogravimetric analyzer (TGA-MS) and heat released in the reaction with a deferential scanning calorimeter (DSC) in open and closed pan. PETN single crystals are used as the samples. The activation energy of decomposition is obtained as a function of extent of reaction by the isoconversional kinetic analysis. The activation energy for the generation of $\mathrm{NO}_{2}(\mathrm{~m} / \mathrm{z}=46)$ in PETN decomposition is consistent with the bond energy of $\mathrm{RO}-\mathrm{NO}_{2}$ in nitrate esters. The activation energy for the overall PETN decomposition is similar to that of the generation of $\mathrm{NO}_{2}$. The effect of confinement on the decomposition kinetics in TGA-MS and DSC, are also discussed in this work. This investigation shows that activation energy for PETN decomposition is in the range of 170-176 kJ/mol.
\end{abstract}

Key Words: Kinetics, PETN, Decomposition, Mass Spectrometry 


\section{Introduction}

Organic energetic materials (OEMs) with high energy density are extensively used in military warhead and mining industries. Application, storage, safe handling and shelf life of

33 OEMs depend on the decomposition process due to the potential of sudden release of extreme

34 heat and sudden expansion of volume of decomposition products [1]. Moreover, initial stages of 35 detonation depend explicitly on the kinetics of decomposition [2]. Hence it is important to investigate the true kinetics of the thermal decomposition of OEMs - to predict the hazard,

37 properties of these materials in long term storage, thermal cook-off, runaway, self-heating, and to 38 design reactors and chemical processes for the production of these compounds [3-5]. Use of inaccurate parameters in predicting the kinetic and thermodynamic properties can cause serious accidents in synthesis, storage and application of OEMs [6-10].

A proper understanding of the decomposition of a benchmark OEM such as

42 Pentaerythritol Tetranitrate (PETN) is required because of its wide applications as a component 43 in propellants and main charges [11]. PETN is a very strong secondary explosive with a high 44 heat of detonation of $1.5 \mathrm{kcal} / \mathrm{gm} \mathrm{[12].} \mathrm{It} \mathrm{has} \mathrm{similar} \mathrm{physical} \mathrm{and} \mathrm{chemical} \mathrm{properties} \mathrm{to} \mathrm{other}$ 45 OEMs. The molecular structure of PETN is shown in Figure 1(a).

A wide range of values, $125-293 \mathrm{~kJ} / \mathrm{mol}$, for the kinetic parameters such as activation

47 energy for PETN decompostion has been previously reported in various studies [13-17]. Other investigations explained the possible pathways, and products, of PETN decomposition at various

49 temperatures [18-20].These studies also showed that the major gas phase components generated 50 from the decomposition of PETN are nitrogen dioxide $\left(\mathrm{NO}_{2}\right)$, nitric oxide $(\mathrm{NO})$, carbon dioxide $51\left(\mathrm{CO}_{2}\right)$, carbon monoxide $(\mathrm{CO})$ and water $\left(\mathrm{H}_{2} \mathrm{O}\right)$. However, gas evolution kinetics resulting from 52 thermal decomposition and its correlation with the safety, storage, handling, thermal cook-off, 
53 initiation and detonation are least understood [3]. The kinetic parameters for each component of 54 the decomposition products are required to develop better thermodynamic and kinetic models 55 for the explanation of the behaviour of energetic materials upon thermal effect. A 56 thermogravimetric analyser combined with a mass spectrometer (TGA-MS) is used for analysing 57 the real-time gas phase products evolved from thermal decomposition [21-22], and can be used 58 to obtain kinetic parameters of thermal decomposition [23]. Since TGA-MS and differential 59 scanning calorimeter (DSC) studies of decomposition are conducted by studying two completely 60 different parameters in two distinct types of confinements of samples, a combined study with 61 these two experimental tools will add new insight into the kinetics of PETN decomposition. The aim of this paper is to understand the non-isothermal reaction kinetics of PETN 63 decomposition from the standpoint of evolved gaseous products and the heat released from the 64 reaction. A single crystal of PETN was used as sample in each experiment. The gas phase 65 products were non-isothermally observed in TGA-MS. To compare the gas evolution kinetics in 66

67 68 70 71 72 73 74 75 
2. Experimental

PETN powder (with a 99.99\% purity) was obtained from Lawrence Livermore National

79 Laboratory. PETN single crystals were grown by following the methods explained elsewhere

80 [25]. Weight of the samples were around $5 \mathrm{mg}$ and thickness of the sample was around $1 \mathrm{~mm}$.

81 Figure 1(b) shows a typical single crystal of PETN. Since samples are single crystal, and sample

82 mass and thickness in the experiments are similar for all the experiments, the effect of particle

83 size, mass and geometry has no effect on the results. Both the DSC (model-Q20) and TGA

84 (model: Q50) were supplied by TA Instruments. The mass spectrometer (model: GSD 320) was

85 obtained from Pfeiffer Vacuum Inc. Vacuum in the MS was maintained at $\sim 1 \mathrm{X} 10^{-6}$ mbar.

86 Helium, with a purity of $>99.99 \%$, was used as a purge gas to minimize any gas phase reaction in

87 TGA-MS. Helium is also passed through the absorption column to eliminate moisture and other

88 impurities. In TGA, the balance purge gas flow rate and the sample purge gas flow rate were 10

$89 \mathrm{~mL} / \mathrm{min}$ and $90 \mathrm{~mL} / \mathrm{min}$, respectively. At these conditions, the time lag between gas evolution

90 and detection in the MS did not influence the results significantly [26]. Experiments in TGA-MS

91 and DSC were performed at the heating rates of 5, 10, 15 and $20 \mathrm{~K} / \mathrm{min}$.

92

93 3. RESULTS AND DISCUSSION

$94 \quad 3.1$ Kinetics of gas evolution from PETN decomposition

95

PETN decomposition is initiated with the hemolytic scission of $\mathrm{O}-\mathrm{NO}_{2}$ bond by 96 releasing $\mathrm{NO}_{2}$ as following equation:

97

$$
\mathrm{RO}-\mathrm{NO}_{2} \stackrel{\text { heat }}{\longrightarrow} \mathrm{RO} \cdot+\mathrm{NO}_{2}
$$


98 The detail reaction mechanism of $\mathrm{NO}_{2}$ release in gas phase is reported in the literature [17, 27].

99 In this investigation, the energy barrier for $\mathrm{NO}_{2}$ production was experimentally obtained by 100 observing the ion current at $\mathrm{m} / \mathrm{z}=46$ in MS. There are no other decomposition products reported 101 in the literature at $\mathrm{m} / \mathrm{z}=46$ that can convolute the TGA-MS curve for $\mathrm{NO}_{2}$. Figure 2 shows $\mathrm{NO}_{2}$ 102 evolution in the reaction as a function of temperature at various heating rates. The $\mathrm{NO}_{2}$ 103 generation increased with increasing temperature; after reaching a maximum value, $\mathrm{NO}_{2}$ 104 generation gradually decreases with increasing temperature. Comparison with the DSC curves, 105 which are presented in Figure 3, shows that $\mathrm{NO}_{2}$ generation is only happened after the melting 106 point. In Figure 3 melting of PETN is appeared at temperature around $142{ }^{\circ} \mathrm{C}$ in the endothermic 107 Peak which is consistent with the literature value [28, 29]. It also demonstrate that, because of 108 using single crystal as sample, evaporation and autocatalysis is not affecting the kinetics of 109 decomposition of PETN.

An isoconversional kinetic analysis of the TGA-MS data was conducted using the KAS 112 model [24] for the first order decomposition

$$
\ln \frac{\beta}{T_{\alpha}^{2}}=\text { Constant }-\frac{E_{a}}{R T_{\alpha}}
$$

114 where $\beta$ is the non-isothermal linear heating rate, $E_{a}$ is the activation energy, $\alpha=\frac{A_{T_{\alpha}}}{A}$ where $115 A_{T_{\alpha}}$ is the area under the curve at any instantaneous temperature, $T_{\alpha}$, and $A$ is the total area under 116 the curve. Here $\alpha$ indicates the cumulative fraction of the completed reaction at temperature $T_{\alpha}$. 117 The activation energy is calculated as a function of extent of reaction from the slope of the 118 straight line of $\ln \frac{\beta}{T_{\alpha}^{2}}$ vs $1 / T_{\alpha}$ plot. 
Figure 4 showed the $\alpha$ for $\mathrm{NO}_{2}$ generation in PETN decomposition as a function of

120

121

122

123

124

125

126

127

128

129

130

131

132

133

134

135

136

137

138

139

140

141

temperature. $\mathrm{T}_{50}$, which is the temperature $\left(T_{\alpha}\right)$ at the completion of $50 \%$ of a reaction, were obtained from Figure 4. In this work, $\mathrm{T}_{50}$ is considered as a characteristic temperature for the comparison of kinetics observed in TGA-MS and DSC. $\mathrm{T}_{50}$ for $\mathrm{NO}_{2}$ production in TGA-MS was found to be at $188,195.8,199.5$ and $201.5^{\circ} \mathrm{C}$ at $5,10,15$ and $20 \mathrm{~K} / \mathrm{min}$, respectively.

$\beta$ and $T$ at various values of $\alpha$ are fitted into equation 2 and plotted in Figure 5. Although a series of lines can be obtained for each value of $\alpha$, only three of the curves are shown from both TGA-MS and DSC for clarity. The linearity of the fit with fitting parameter $\mathrm{R}^{2} \sim 0.99$ shows that $\mathrm{NO}_{2}$ evolution from PETN decomposition follows similar reaction order at each $\alpha$.

The activation barrier for the $\mathrm{NO}_{2}$ generation in PETN decomposition as a function of $\alpha$ is obtained from the above analysis shown in Figure 6. The activation energy for the decomposition is similar in the entire range of $\alpha$. Experimental values of activation energy for $\mathrm{NO}_{2}$ release from PETN are found to be between 168 to $181 \mathrm{~kJ} / \mathrm{mol}$ with an average activation energy of $175.8 \mathrm{~kJ} / \mathrm{mol}$. Figure 6 also shows that experimental value is consistent with the theoretical value of $\mathrm{RO}-\mathrm{NO}_{2}$ bond energy in nitrate ester that is $170.3 \mathrm{~kJ} / \mathrm{mol}$ [14]. To the best of our knowledge, this is the first experimental demonstration of obtaining the activation energy of $\mathrm{NO}_{2}$ generation from the decomposition of PETN.

The ion current for the component at $\mathrm{m} / \mathrm{z}=30$ was also observed in MS. Previous studies showed that both $\mathrm{NO}$ and $\mathrm{CH}_{2} \mathrm{O}$ are decomposition products at $\mathrm{m} / \mathrm{z}=30$ [20]. A similar activation energy for this component was obtained as for the generation of $\mathrm{NO}_{2}$. The ion current for the component at $\mathrm{m} / \mathrm{z}=18$, which is most likely water $\left(\mathrm{H}_{2} \mathrm{O}\right)$ since there are 8 hydrogen and 12 oxygen atoms in PETN structure, was also observed, and is shown in Figure 7. The activation energy of this component was obtained at $84-143 \mathrm{~kJ} / \mathrm{mol}$ by analysing Figure 7 and shown in 
142 Figure 6. Initially activation energy increase from $\alpha=0.1$ to $\alpha=0.3$, and then activation energy is

143 almost constant at $\alpha>0.3$. The exact mechanism for the observed trend cannot be explained from

144 this study but suggests that there may be multiple pathways for the evolution of water based on 145 heating rate.

\subsection{Isoconversional Kinetic Analysis of Heat Release in Reaction}

The kinetics of $\mathrm{NO}_{2}$ generation in PETN decomposition observed by TGA-MS is then compared with that of overall PETN decomposition investigated by studying the exothermic heat release in the reaction using a DSC. Figure 3 shows the DSC thermograms of PETN that are obtained by running the experiments in closed pan and open pan. Figure 4 compares the $\alpha$ from DSC experiment with that of TGA-MS at various heating rates. $\alpha$ in both experiments shifts to the right with increasing heating rate. For $\alpha=0.5$, the $\mathrm{T}_{50}$ from DSC experiment shifts to 197.4, $154204.3,208.9$ and $212.6{ }^{\circ} \mathrm{C}$ for the heating rate of 5, 10, 15 and $20 \mathrm{~K} / \mathrm{min}$, respectively. It is evident from Figure 4 that $\mathrm{T}_{50}$ in DSC experiment is around $10{ }^{\circ} \mathrm{C}$ higher compared to the $\mathrm{T}_{50}$ in

156 TGA-MS experiment. Figure 4 also shows that differences of the decomposition temperature in 157 DSC and TGA-MS increase with the increasing temperature. This effect may be due to the 158 confinement of the sample because the samples in DSC is run in crimped pan; on the other hand 159 samples in TGA-MS are run in open pan. To test this hypothesis, experiments with open pans

160 are also conducted in DSC that are shown in Figure 3. Comparison of $\alpha$ in Figure 4 shows that $161 \mathrm{~T}_{50}$ for open pan DSC is much closer to the results of TGA-MS. Moreover, $\mathrm{T}_{\alpha}$ for $\mathrm{NO}_{2}$ 162 generation and decomposition of PETN in open pan DSC is even closer at lower value of $\alpha$ $163(\alpha<0.3)$. At this range of $\alpha$, difference in $\mathrm{T}_{\alpha}$ at these values of $\alpha$ can be mainly attributed to 164 evaporation of samples in an open pan. 
Figure 5 compares the KAS plots ( $\ln \frac{\beta}{T_{\alpha}^{2}}$ vs $1 / T_{\alpha}$ ) of $\mathrm{NO}_{2}$ generation with that of overall

167 PETN decomposition in open and closed pan. As mentioned earlier, only the plot at $\alpha=0.1,0.50$

168 and 0.70 are shown for clarity of the Figure 5. These curves qualitatively compares kinetics of

169 the decomposition. $\mathrm{NO}_{2}$ gas evolution and overall PETN decomposition kinetics in closed and 170 open pan shows identical linear behavior following a similar reaction order at all values of $\alpha$;

171 although the slope of the curve for PETN decomposition in open pan at $\alpha=0.5$ is different from 172 the other two which indicates a different activation energy at this condition. Figure 5 also 173 demonstrate that, for PETN decomposition, the order of reaction is not influenced by the 174 confinement of samples. At $\alpha=0.1$, KAS plot for $\mathrm{NO}_{2}$ generation and decomposition in open pan 175 is almost similar showing a similar slope and intersection.

Figure 6 compares activation energy, as a function of extent of reaction, of $\mathrm{NO}_{2}$ 178 generation with that of overall PETN decomposition in closed and open pan. The activation 179 energy for overall decomposition studied in closed pan is almost constant in the whole range of $180 \alpha$, and the average value of activation energy is $170 \mathrm{~kJ} / \mathrm{mol}$. As shown in Figure 6, this result is 181 consistent with the activation energy for the scission of $\mathrm{NO}_{2}$ group from the PETN structure 182 observed in TGA-MS. Activation energy for the decomposition of PETN obtained from open 183 pan experiment is also shown in Figure 6, which shows that the activation energy at $\alpha=0.1$ from 184 open pan experiment is almost same with the activation energy obtained from closed pan 185 experiment and also with that of $\mathrm{NO}_{2}$ generation. At $\alpha>0.2$, activation energy obtained from open 186 pan experiment is lower compared to that of closed pan as well as the activation energy of $\mathrm{NO}_{2}$ 187 generation. At these value of $\alpha$, heat released per unit mass of sample is not accurately observed 
188 in open pan experiments as the Figure 2 shows that heat release in open pan is less than that in 189 closed pan; moreover evaporation of PETN will be high and can convolute the decomposition 190 kinetics which cause a faster decomposition with low activation energy.

191 However, kinetics of decomposition investigated by the DSC and the TGA-MS showed 192 that decomposition of PETN might be limited by the scission of $\mathrm{NO}_{2}$ group from PETN 193 structure.

\section{Conclusion}

In summary, we explained the non-isothermal decomposition kinetics of PETN by studying both the products and reactants by a TGA-MS and DSC respectively. The activation energy for $\mathrm{NO}_{2}$ showed similar values in the whole conversion range. Average activation energy of $\mathrm{NO}_{2}$ production is $\sim 175.8 \mathrm{~kJ} / \mathrm{mol}$. This is consistent with the theoretical value $\mathrm{RO}-\mathrm{NO}_{2}$ bond energy. Isoconversional kinetic analysis by the DSC observation in closed pan showed that 203 activation energy of PETN decomposition is almost constant $(\sim 170 \mathrm{~kJ} / \mathrm{mol})$ across $\alpha=0.1-0.9$, 204 and consistent with the activation energy of the generation of $\mathrm{NO}_{2}$ from PETN decomposition. 205 This indicates that dissociation $\mathrm{NO}_{2}$ from PETN structure might be the rate limiting steps for the 206 PETN decomposition. Activation energy of PETN, obtained from open pan DSC, are lower 207 compared to the activation energy obtained from closed pan DSC and TGA-MS experiments. 208 From this study, we conclude that activation energy for PETN decomposition is in the range of $209 \sim 170-176 \mathrm{~kJ} / \mathrm{mol}$. 


\section{ACKNOWLEDGEMENT}

212 The authors are grateful for support received from ONR (N00014-11-1-0424) and the U.S. 213 Department of Homeland Security under Award Number 2008-ST-061-ED0001. The views and

214 conclusions contained in this document are those of the authors and should not be interpreted as 215 necessarily representing the official policies, either expressed or implied, of the U.S. Department 216 of Homeland Security.

217 


\section{References}

[1] B. Roduit, M. Hartmann, P. Folly, A Sarbach, P. Brodard, R Baltensperger. Determination of thermal hazard from DSC measurements.Investigation of self-accelerating decomposition temperature(SADT) of AIBN, J. Therm. Anal.Cal., 2014, 117, 1017-1026.

[2] W. E. Garner. Detonation or explosion arising out of thermal decomposition Trans. of the Faraday Soc. 1938, 34, 985-989.

[3] D. A. Crowl, J. F. Louvar. Chemical Process Safety: Fundamentals with Applications. Third Ed, Boston, USA, May 2011.

[4] S. Vyazovkin, A. Burnham, J. M. Criado, L. A. Pérez-Maqueda, C. Popescu, N. Sbirrazzuoli. ICTAC Kinetics Committee recommendations for performing kinetic computations on thermal analysis data. Thermochim. Acta, 2011, 520, 1-19.

[5] B. Roduit, M. Hartmann, P. Folly, A. Sarbach, P. Brodard, R. Baltensperger. Prediction of thermal stability of materials by modified kineticand model selection approaches based on limited amountof experimental points. Thermochim. Acta, 2014, 579, 31-39.

[6] S. V. Vyazovkin, A. I. Lesnikovich. Error in determining activation energy caused by the wrong choice of process model. Thermochim. Acta, 1990, 165, 11-15.

[7] N. Koga, J. Sestak, J. Malek. Distortion of the arrhenius parameters by the inappropriate kinetic model function. Thermochim. Acta, 1991, 188, 333-336.

[8] A. Kossoy, Y. Akhmetshin. Identification of kinetic models for the assessment of reaction hazards. Process safety progress. 2007, 26(3), 209-220.

[9] A. K. Burnham, D. M. Hoffman, P. C. Souers, F. J. Gagliardi, T. Tran, R. K. Weese, J. G. Koerner, and S. C. DePiero. What Have We Learned From Decades of CRT, And Where Do We Go From Here? Livermore National Laboratory, UCRL-CONF-224457, 2006. 
242 [10] A. K. Galwey. Perennial problems and promising prospects in the kinetic analysis of 243 nonisothermal rate data. Thermochim. Acta, 2003, 407, 93-103.

244 [11] A. K. Burnham, S. R. Qiu, R. Pitchimani, B. L. Weeks. "Comparison of kinetic and 245 thermodynamic parameters of single crystal pentaerythritol tetranitrate using atomic force 246 microscopy and thermogravimetric analysis: Implications on coarsening mechanisms." Journal 247 of Applied Physics, 2009, 105(10), 104312.

248 [12] Y. Hori, L. Davidson, N. Thadhani. High-Pressure Shock Compression of Solids VI. 249 Springer, $1^{\text {st }}$ ed, 2003.

250 [13] F. J. Dicarlo, J. M. Hartigan, G. E. Phillips. Analysis of pentaerythritol tetranitrate and its 251 hydrolyis products by thin layer chromatography and radio scanning. Anal. Chem., 1964, 36, $252 \quad 2301-2303$.

253 [14] D. Chamber. Perspectives on pentaerythritol tetranitrate (PETN) decomposition. Lawrence 254 Livermore National Laboratory, UCRL-JC-148956,July 1, 2002.

255 [15] G. D. Miller, L. D. Haws, R. H. Dinegar. Kinetics of the thermal decomposition of PETN. $25619^{\text {th }}$ International Symposium on Combustion 1982.

257 [16] J. S. Lee, C. K. Hsu, C. L. Chang. A Study on the thermal decomposition behavior of 258 PETN, RDX, HNS and HMX. Thermochim. Acta, 2002, 392-393,173-176.

259 [17] P. S. Makashir, E. M. Kurian. Spectroscopic and thermal studies on pentaerythritol 260 tetranitrate (PETN). Propellants Explos. Pyrotech., 1999, 24, 260-265.

261 [18] M. A. Hiskey, K. R. Brower, J. C. Oxley. Thermal decomposition of nitrate esters. The 262 Journal of Physical Chemistry. 1991, 95(10), 3955-3960. 
[19] Z. A. Dreger, Y. A. Gruzdkov, Y. M. Gupta, J. J. Dick. Shock wave induced decomposition chemistry of pentaerythritol tetranitrate single crystals: Time-resolved emission spectroscopy. $J$. Phys. Chem. B, 2002, 106, 247-256.

[20] X. Ruijuan, L. Hong, L. Shunhuo, L. Jiabin. A study on thermal decomposition of PETN by PGC/MS. Proceedings of the $3^{\text {rd }}$ international autumn seminar on propellants, explosives, 1999, 153-159.

[21] G. Jian, Z Lei, N. W. Piekiel, M. R. Zachariah. Low Effective Activation Energies for Oxygen Release from Metal Oxides: Evidence for Mass-Transfer Limits at High Heating Rates. ChemPhysChem, 2014, 15(8), 1666-1672.

[22] E. Lopez-Capel, R. Bol, D. A. C. Manning. Application of simultaneous thermal analysis mass spectrometry and stable carbon isotope analysis in a carbon sequestration study. Rapid communications in mass spectrometry. 2005, 19(22), 3192-3198.

[23] A. K. Burnham, R. K. Weese, A. P. Wemhoff, J. L. Maienschein, A historical and current perspective on predicting thermal cookoff behavior. Journal of thermal analysis and calorimetry, 2007, 89(2), 407-415.

[24] T. Akihara, T. Sunose. Method of determining activation deterioration constant of electrical insulating materials. Res. Report Chiba Ins. Technol. (Sci. Technol.)1971, 16, 22-31.

[25] S. K. Bhattacharia, A. Maiti, R. H. Gee, B. L. Weeks. Sublimation Properties of Pentaerythritol Tetranitrate Single Crystals Doped with Its Homologs. Propellants Explos. Pyrotech., 2012, 37, $563-568$.

[26] B. Roduit, J. Baldyga, M. Maciejewski, A. Baiker. Influence of mass transfer on interaction between thermoanalytical and mass spectrometric curves measured in combined thermoanalysermass spectrometer systems. Thermochemical Acta, 1997, 295, 59-71. 
287 NC). Propellants Explos. Pyrotech. 1989, 14, 89-92.

288 [28] R. Meyer, J. Köhler, and A. Homburg, Explosives: John Wiley \& Sons, 2008.

289 [29] T. R. Gibbs, LASL explosive property data vol. 4: Univ of California Press, 1980.

290

291

292

293

294

295

296

297

298

299

300

301

302 
303

304

305

306

307

308

309

310

311
Figure 1(a): Molecular structure of PETN

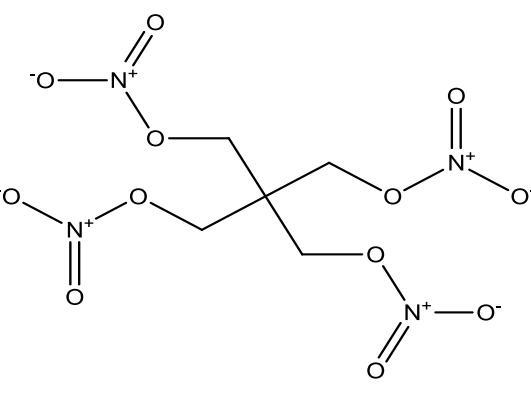

pentaerythritol tetranitrate

Figure 1(b): PETN single crystal

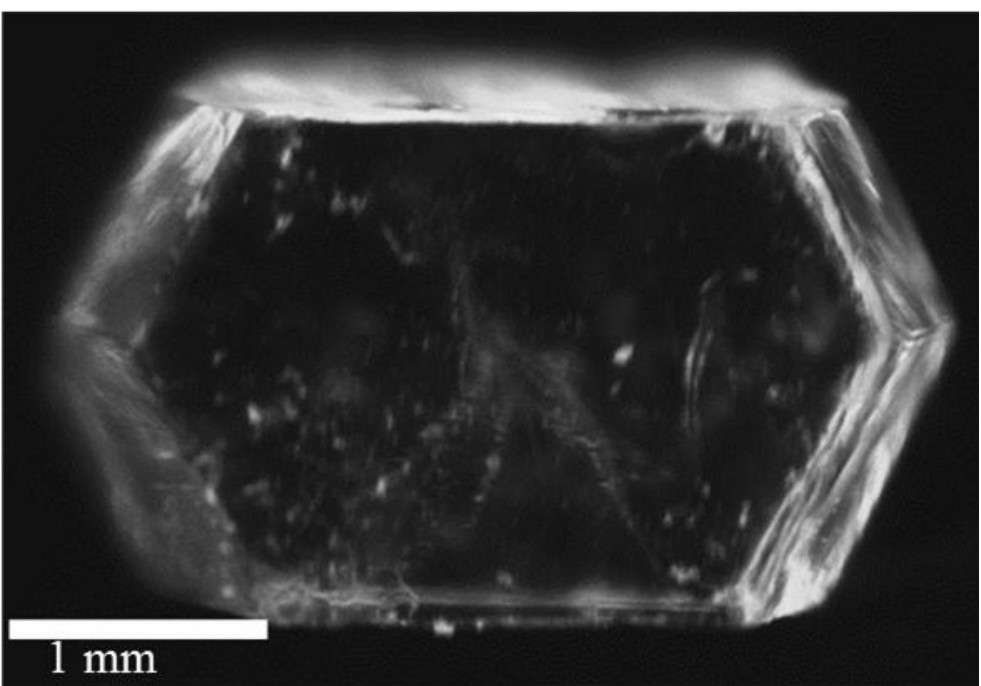


312 Figure 2: $\mathrm{NO}_{2}$ evolution from PETN decomposition observed in TGA-MS.

313

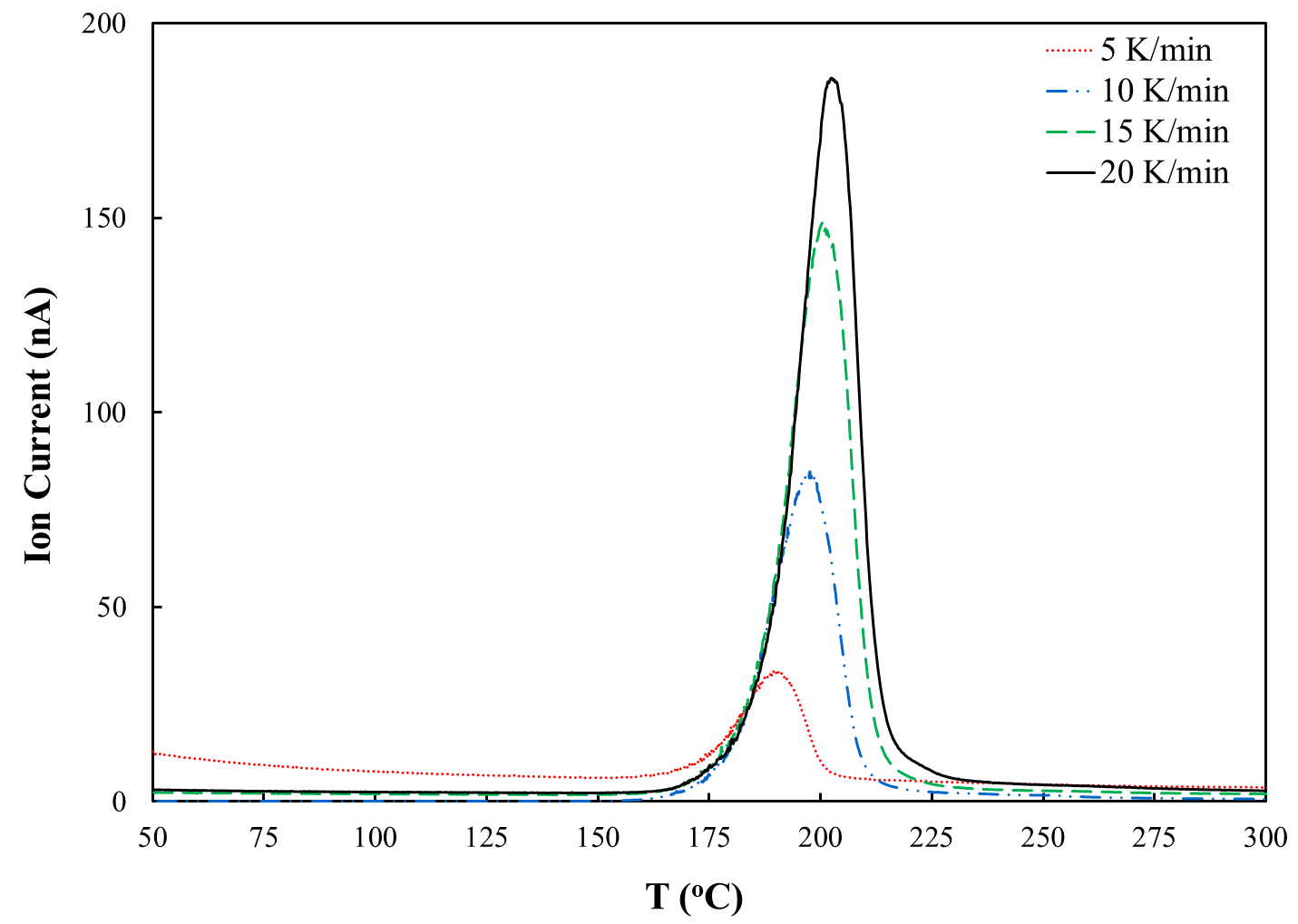

314

315

316

317

318

319

320

321

322

323

324

325

326

327 
328 Figure 3: PETN single crystal in DSC at various heating rate in open and closed pan.

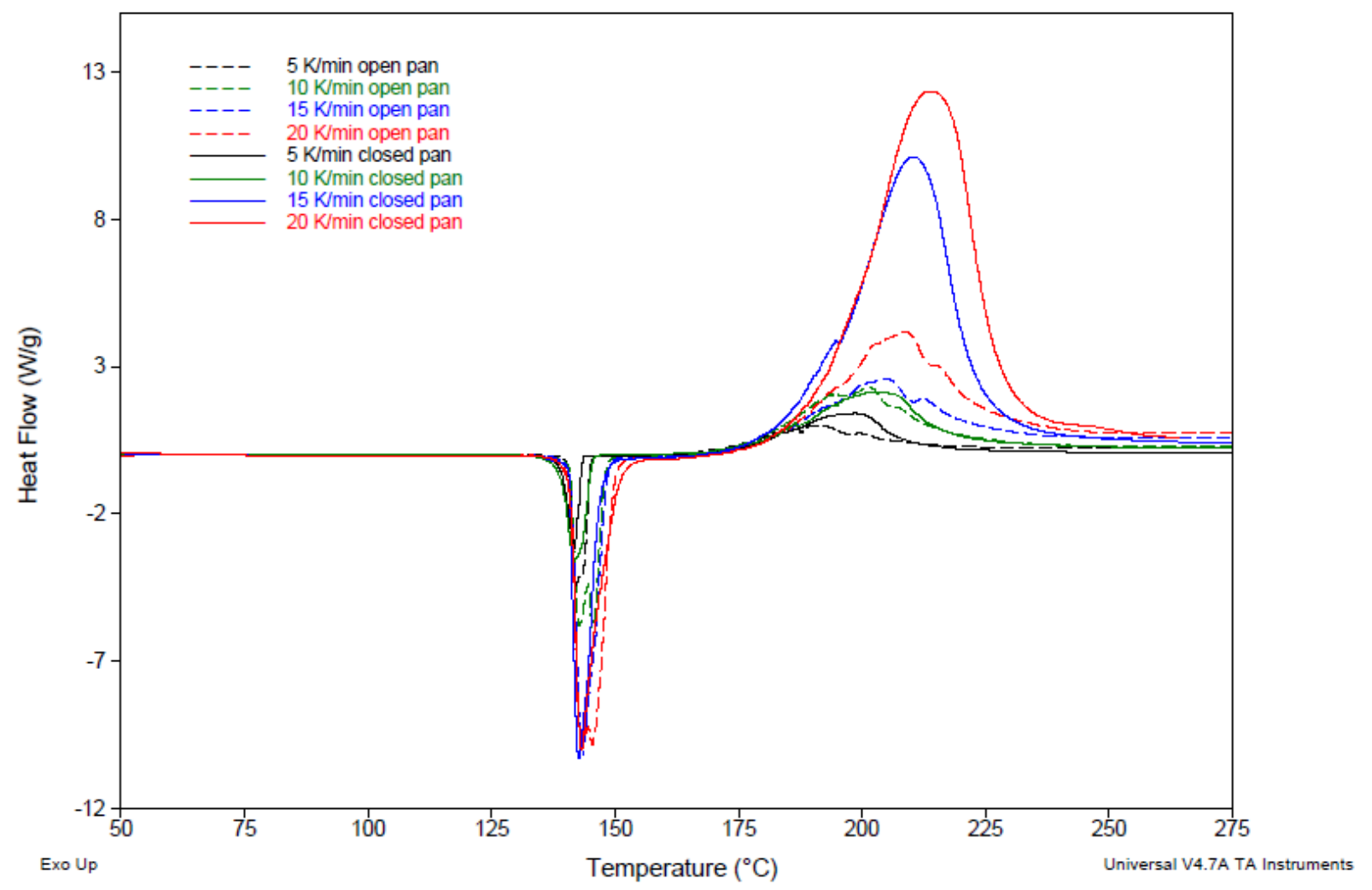

329

330 
332 Figure 4: Comparison of the extent of reaction of $\mathrm{NO}_{2}$ generation observed in TGA-MS and 333 overall PETN decomposition observed in DSC.

334

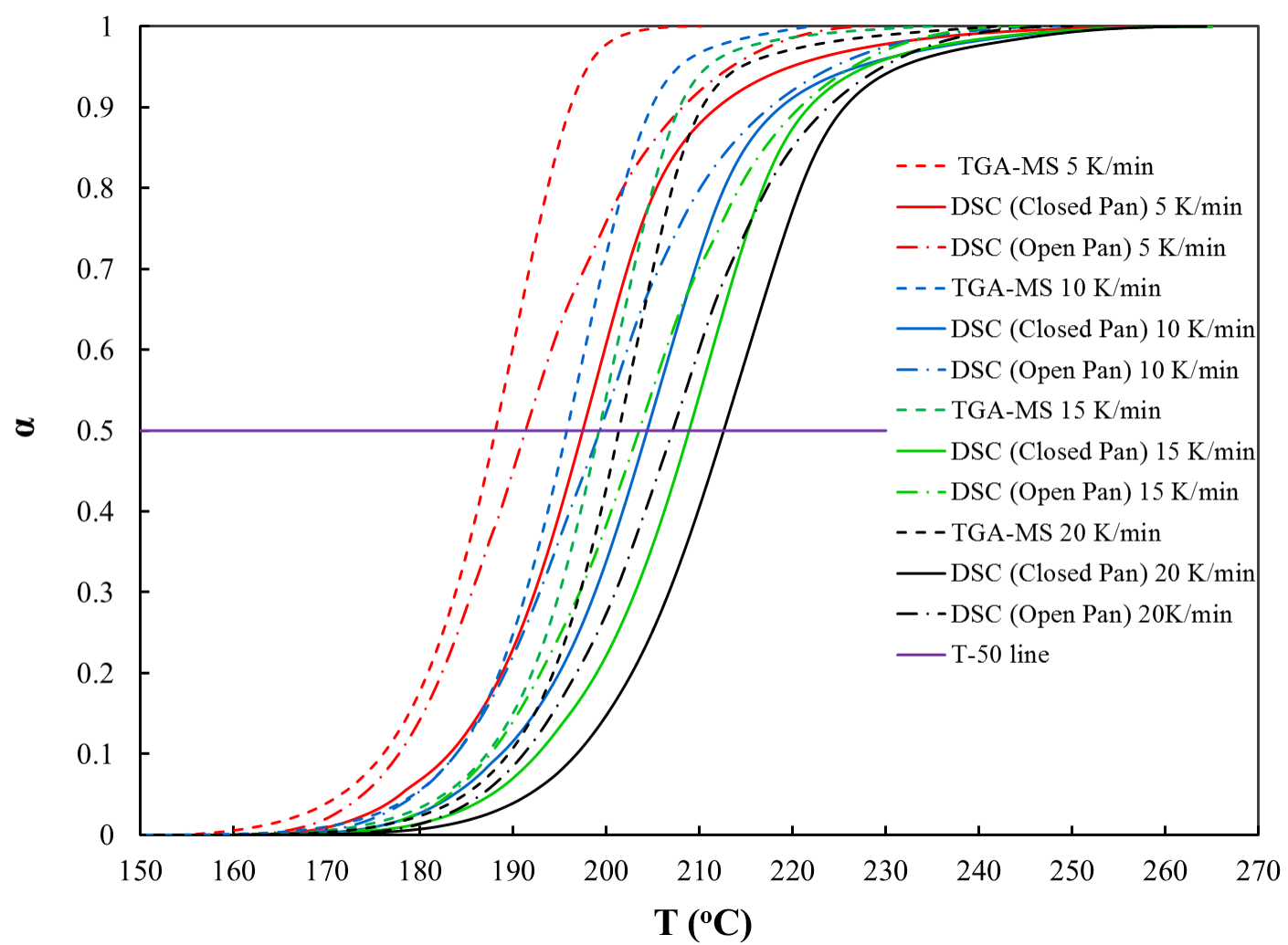

335

336

337

338 
339 Figure 5: KAS plot, showing the decomposition kinetics, of gas evolution observed in TGA-MS 340 and over all decomposition observed in DSC; here — for TGA-MS, — for DSC Open Pan 341 and - for DSC Closed Pan.

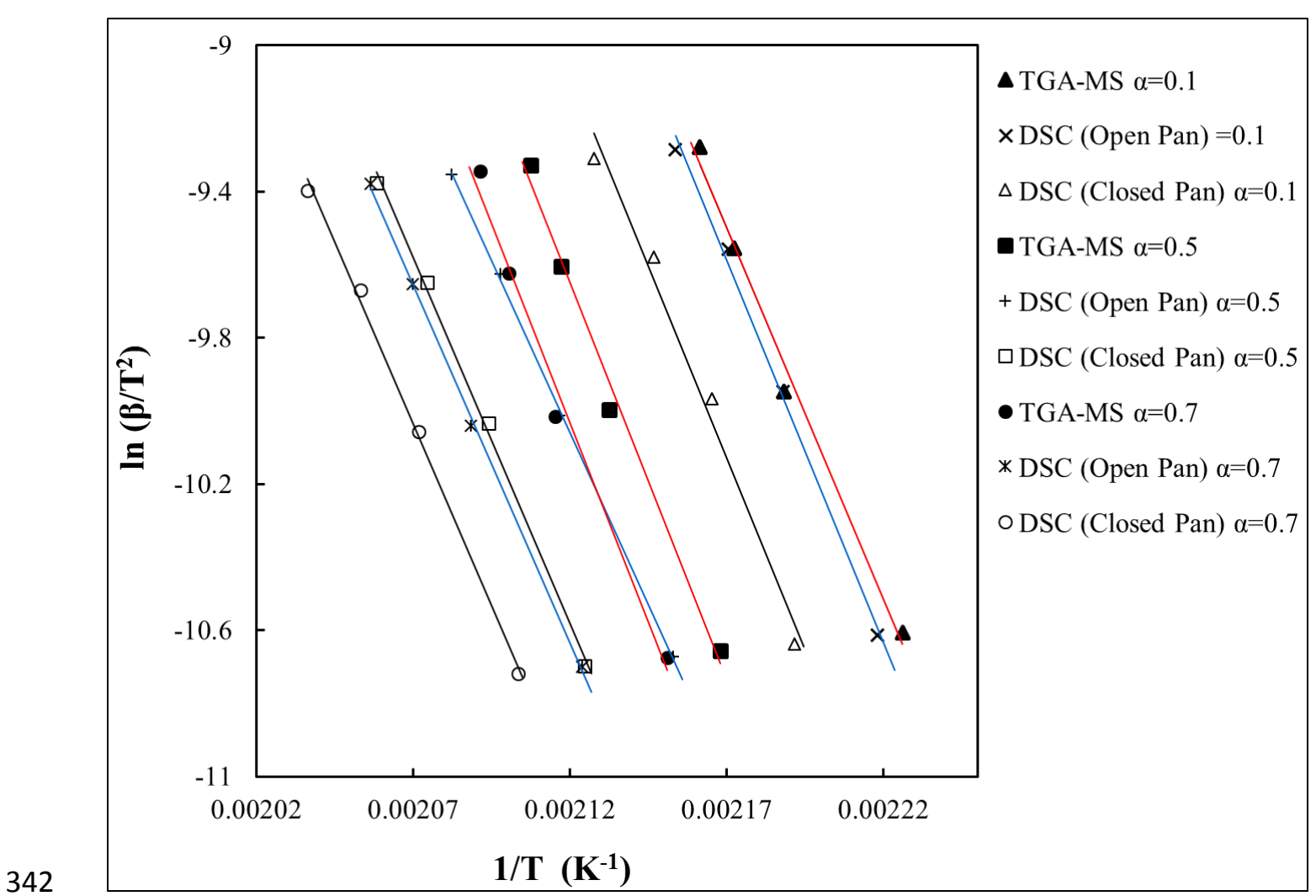


344 Figure 6 : Comparison of activation energy of PETN obtained from gas evolution kinetics 345 observed by a TGA-MS and heat released from the reaction observed in DSC.

346

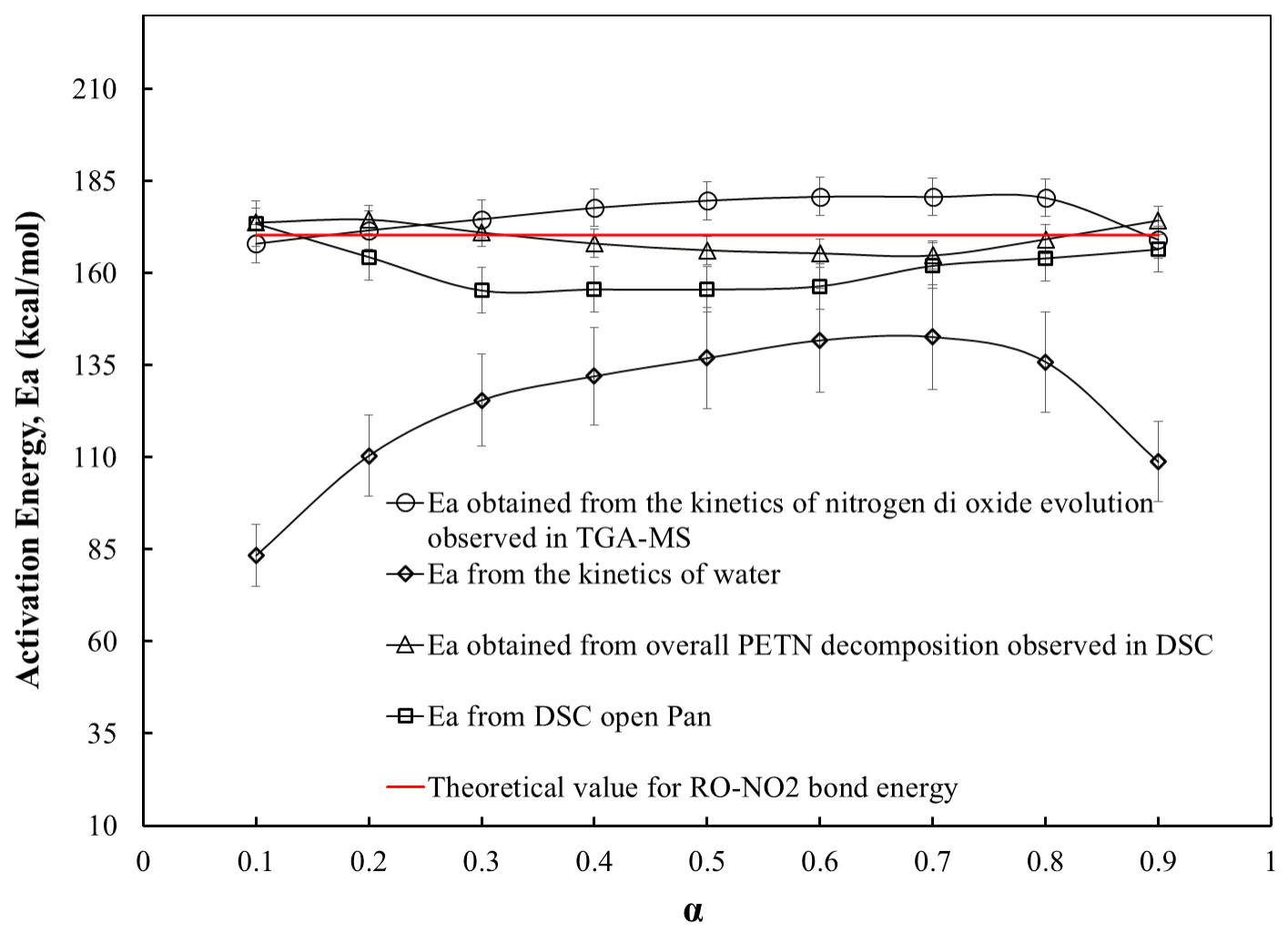

347

348

349

350

351

352

353

354

355

356

357

358

359 
361 Figure 7: $\mathrm{H}_{2} \mathrm{O}$ evolution from PETN decomposition observed in TGA-MS.

362

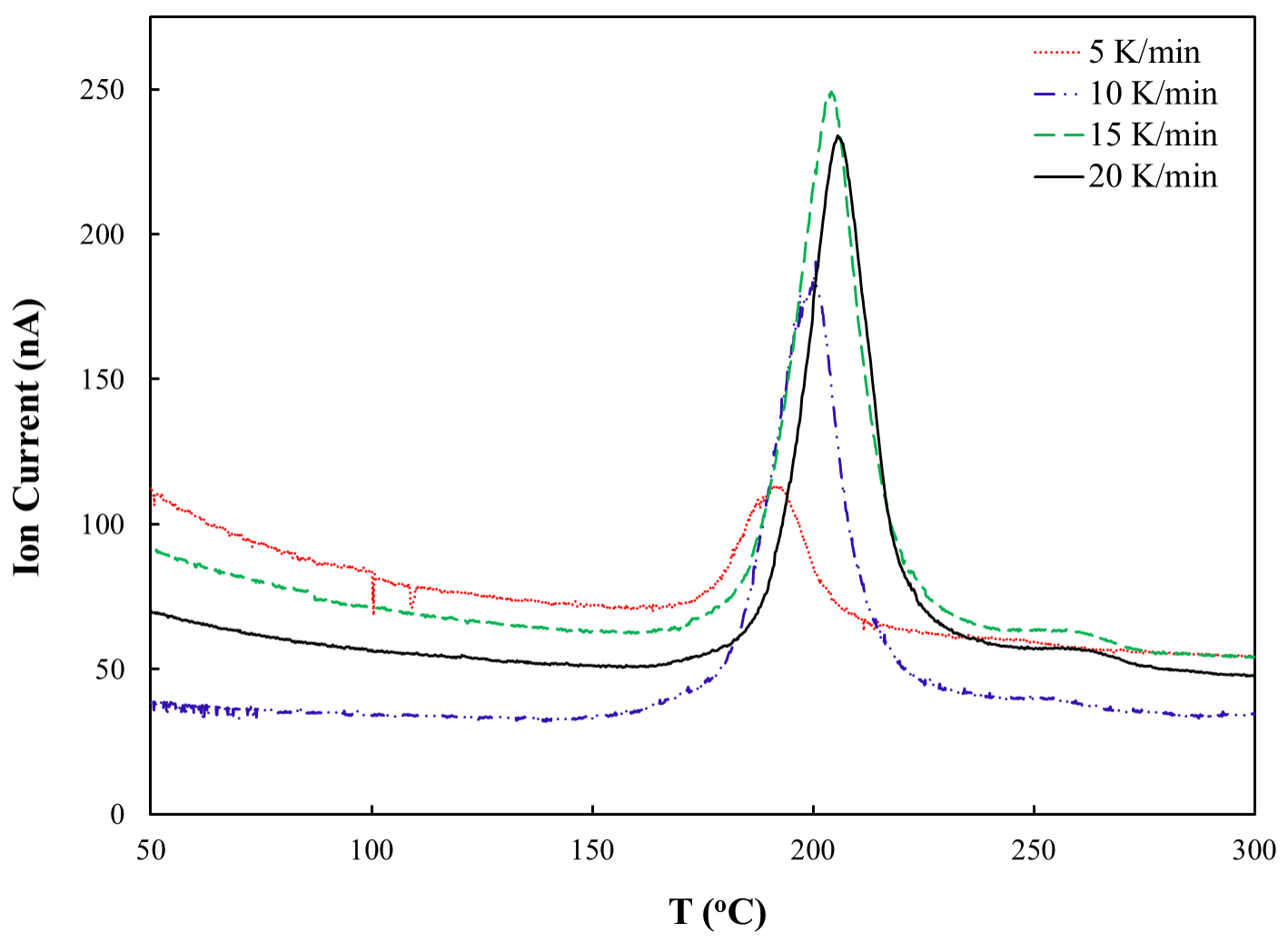

